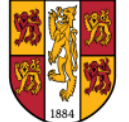 \\ PR I F YS G OL \\ B ANGOR \\ UNIVERSITY \\ Estimating ecological social capital using multi-level regression with post- stratification: A spatial analysis of psychiatric admission rates in Wales
}

Saville, Christopher W.N.

\section{Health and Place}

DOI:

10.1016/j.healthplace.2019.102187

Published: 01/09/2019

Peer reviewed version

Cyswllt i'r cyhoeddiad / Link to publication

Dyfyniad o'r fersiwn a gyhoeddwyd / Citation for published version (APA):

Saville, C. W. N. (2019). Estimating ecological social capital using multi-level regression with post-stratification: A spatial analysis of psychiatric admission rates in Wales. Health and Place, 59, [102187]. https://doi.org/10.1016/j.healthplace.2019.102187

\footnotetext{
Hawliau Cyffredinol / General rights

Copyright and moral rights for the publications made accessible in the public portal are retained by the authors and/or other copyright owners and it is a condition of accessing publications that users recognise and abide by the legal requirements associated with these rights.

- Users may download and print one copy of any publication from the public portal for the purpose of private study or research.

- You may not further distribute the material or use it for any profit-making activity or commercial gain

- You may freely distribute the URL identifying the publication in the public portal ?
}

Take down policy

If you believe that this document breaches copyright please contact us providing details, and we will remove access to the work immediately and investigate your claim. 
Estimating ecological social capital using multi-level regression with poststratification: A spatial analysis of psychiatric admission rates in Wales

Christopher W. N. Saville ${ }^{1}$

North Wales Clinical Psychology Programme, School of Psychology, Bangor University, Wales

ORCID ID: 0000-0003-4870-7630

\section{Corresponding Author:}

Chris Saville

North Wales Clinical Psychology Programme,

School of Psychology,

Brigantia Building,

Penrallt Road

Bangor University,

Bangor, Gwynedd

Wales

LL57 2AS

Email: c.saville@bangor.ac.uk

Tel: 01248388740

Word count: 5298

\section{ACKNOWLEDGEMENTS:}

I would like to thank the survey team at the Welsh Government and NHS Wales Informatics Service for access to the data, as well as the two anonymous reviewers for their helpful comments. I have no conflicts of interest to declare. 


\section{Abstract}

Although ecological cognitive social capital is an important predictor of mental health, measurement remains crude. Multi-level regression with post-stratification (MRP) is a technique for computing small area estimates of survey responses, used in political science but hitherto not for estimating ecological protective factors in epidemiology. National Survey for Wales 2016-17 data $(\mathrm{N}=10,486)$ were used to produce MRP estimates of belonging and generalised trust for 410 middle super output areas covering Wales. These estimates were used to predict psychiatric admission rates in 2017 ( $\mathrm{N}=9978$ cases).

Low belonging and trust are ecological risk factors for psychiatric admissions, with a $29 \%(25-33 \%)$ and 25\% (22-29\%) increase in admissions per standard deviation decrease respectively. Equivalent results for using standard simple aggregation of survey data by area suggest $8 \%(4-12 \%)$ and 10\% (6-14\%) increases in risk per standard deviation.

MRP has potential for studying ecological risk factors based on self-report measures, with greater predictive validity for incidence of psychiatric admissions than current methods.

Keywords: Spatial epidemiology; Small-Area Analysis; Generalized trust; Belonging; Social epidemiology 
Cognitive social capital, one's beliefs about the community where they live[1], is an important predictor of health[2]. A systematic review found that low cognitive social capital, but not structural social capital - formal structures and practices underpinning community[1], is a risk factor for mental health problems[3]. Individual-level cognitive social capital partly accounts for this- people with low cognitive social capital have poor health outcomes[4] - but some risk appears to be ecological. After accounting for individual cognitive social capital, living in a community where others have low cognitive social capital, namely ecological social capital, is itself a risk factor for poor mental health[5].

The causal mechanisms underpinning this association are less clear. Explanations can be broadly divided into compositional and contextual accounts[e.g. 6]. Compositional accounts suggest that people predisposed to, or with existing, mental health problems move to particular types of area, causing a decline in social and economic capital[7]. Contextual accounts, by contrast, propose the opposite causal direction, with areas with high social capital promoting good mental health by facilitating and enriching residents' lives[3,8].

Although its theoretical and empirical importance is clear, measuring ecological social capital is challenging. Unlike other social risk factors like material deprivation, it is not captured by administrative data and must be measured using self-report surveys. Even large-scale surveys, however, sample a tiny proportion of the population, so the way such data are transformed from the individual to the ecological level is important. Previous ecological analyses of cognitive social capital have simply averaged survey responses within geographical units, a method hereafter called simple aggregation. 
This is problematic for two reasons. Firstly, unless the sample is unusually large, the margin of error for each area is likely to be unacceptably wide due to sampling variation - an area where $\sim 25$ of $\sim 6000$ residents were sampled (the average situation for the data described below) would have a 95\% margin of error of 15-20 percentage points either way. Secondly, attempts to make a sample representative, either in terms of data collection or in terms of reweighting, typically focus on making the overall sample representative of the population, rather than each ad hoc geographical subset of respondents. Thus the respondents for each geographical unit will be a) far too few in number and b) potentially systematically unrepresentative to estimate the variable of interest at the local level.

\section{Multi-level regression with post-stratification}

Techniques to solve these problems exist in political science. Multi-level regression with post-stratification (MRP) $[9,10]$ is a method for estimating average responses to a survey item at smaller units of geography than the survey was designed for. It has generally been applied to voting intention data, but the same principles hold for other types of survey data.

MRP involves fitting a multi-level regression model to the survey item of interest using individual-level (e.g. sex, national identity) and area-level (e.g. unemployment rate) variables as random and fixed effects respectively. Random effect terms are also fitted for each geographical unit to capture additional variance unaccounted for by the predictors identified. 
An estimate for the average response of each combination of the individual variables (e.g. British-identifying women aged 20-24) can then be made and these values can be summed for each geographic unit, weighted by their share of the population there (based on census data or similar), and combined with area-level predictors to produce estimated average responses for each geographical unit.

Applications using simulated and real data show that MRP outperforms simple aggregation[11]. Instead of considering respondents from each geographical unit separately, MRP uses the entire sample to model the target response. Area-level predictors have also been shown to greatly improve estimates[12]. MRP estimates can theoretically be made for geographical units which have no respondents at all in the original survey, by assuming that the individual-level and area-level predictors are valid out of sample. Furthermore, it has been shown to yield reasonable results even with non-representative samples[13].

\section{The present study}

The present study produces MRP estimates of neighbourhood cognitive social capital and uses them to predict psychiatric admission rates in Wales. Cognitive social capital is operationalised using questions measuring sense of belonging and generalised trust. Which constructs comprise social capital and which do not is a contested topic $[14,15]$. Trust is a key part of Putnam's influential conception of social capital [16] and is a feature of most measures of social capital [17], while sense of belonging, although arguably more of a product of a Durkheimian concept of social cohesion than of social capital[18], is widely deployed as a measure of social capital in social epidemiology and appears well correlated with network measures of social capital[14]. The predictive 
validity of MRP estimates is compared to that of simple aggregation estimates. Social capital and admission rates are measured independently using two sources of data, the 2016-17 National Survey for Wales and the Patient Episode Database for Wales respectively.

\section{METHODS}

Ethical approval was granted by the School of Psychology, Bangor University and by a National Health Service Research Ethics Committee (Wales 4).

\section{MRP estimates}

The 2016-17 National Survey for Wales[19], was used to produce MRP estimates of sense of belonging and generalised trust for middle super output areas (MSOA). MSOAs are units of UK Census geography designed to provide comparably sized and fairly homogenous areas to improve small area statistical reporting. Their populations, when drawn after the 2011 census, ranged between 5000 and 15,000.

\section{Sample}

The National Survey for Wales is an annual survey commissioned by the Welsh Government, examining a range of topics. Sampling was based on a random selection of postal addresses, stratified by local authority, with a $54.6 \%$ response rate.

The total $\mathrm{N}$ was 10,493 but after removing participants with missing data for any variable required for analysis, 10,486 respondents (99.9\%) remained. Respondents were available for all MSOAs, with a mean of 25.58 per MSOA (range: 6-103, interquartile range: $17-29)$. 
Demographic variables were recoded to correspond to UK Census table DC2203WA 'Ability to speak Welsh by national identity by sex by age' as follows. Participant ages were reduced to five year age bands for those between 20 and 84, plus additional 16-17, 18-19, and 85 and over bands. National identity was coded as Welsh only, Welsh and British, British only, English and British, English only, and All other identities. Ability to speak Welsh was already dichotomised, but those who had spontaneously claimed to have 'some speaking ability' (8\%) were categorised as non-Welsh speakers.

\section{Measures}

Cognitive social capital was operationalised using two questions. Belonging was measured using responses to the statement 'I belong to my local area', where respondents rated their agreement on a five-point Likert scale. Responses were dichotomised (Likert responses are not interval data) so those who responded 'strongly disagree' or 'tend to disagree' had a value of 0 and those who responded 'strongly agree', 'tend to agree', or 'neither agree nor disagree' had a value of 1.

Generalised trust was measured using the question: 'Would you say that most people can be trusted? Please answer on a scale from nought to 10 where nought means that in general you do not trust any other person and 10 that you feel most people can be trusted.' Here, data were dichotomised so $0-4$ were categorised as 0 and 5-10 as 1 . This was done on the basis of a clear point of inflection between the number of respondents answering $4(<5 \%)$ and $5(>20 \%)$. 
Churn data[20], measuring the proportion of households in each lower super output area where the occupant had changed between 2017 and, in this case, 2014, were aggregated at MSOA level by taking the mean value of the constituent lower super output areas for each MSOA.

The proportion of each MSOA in receipt of unemployment-related benefits for 2017 was taken from the Welsh Government's Welsh Index of Multiple Deprivations (http://wimd.wales.gov.uk/) indicator data. Population density and the proportion of residents aged 16+ with no formal qualifications were taken from the 2011 UK Census.

\section{Multi-level regression}

Binomial generalised linear mixed effects models were fitted to the data using the lme4 package[21] for R[22]. The belonging and trust models had identical random effects structures: Random intercepts of MSOA, age band, and gender were included, as was a random slope of Welsh-speaking and national identity for each local authority. The cultural significance of Welsh-speaking and national identity were expected to vary throughout Wales[23,24] so these coefficients were allowed to vary geographically[25]. For belonging, fixed effects of churn and unemployment were used as area-level predictors; for trust, fixed effects of population density and proportion of residents with no formal qualifications were used.

These variables were chosen on the basis of theoretical expectations about what factors might promote or disrupt social capital (e.g. churn, Welsh language and national identity varying by local authority), on the basis of their broader prominence in social science (e.g. age, sex, rurality, unemployment, education), and on the availability of 
cross-tabulated census data for the variables in question at the MSOA level (not all combinations of census data are available, for reasons of identifiability). The final model specifications were based on a small amount of experimentation into what variables helped to predict belonging and trust in the survey data, but importantly not on the basis of which combination of variables best predicted psychiatric admissions. Such decisions were undoubtably assumption-laden and this will be revisited in the discussion.

\section{Post-stratification}

The coefficients from the mixed effects models were then post-stratified using census data to produce estimates of belonging and trust for each MSOA.

Census table DC2203WA was downloaded using nomisr[26] and the proportion of each MSOA's population in each age*sex*national identity*Welsh-speaking stratum was computed.

Each MSOA*age*sex*national identity*Welsh-speaking cell of the census had the appropriate level of the age, gender, national identity, and Welsh-speaking random effects from the mixed effects model applied to it (For Welsh-speaking and national identity, the random effect for the relevant local authority was used), before values for all strata within each MSOA were summed, weighted by the proportion of the population of the MSOA that each cell represented, so that where a demographic group were numerous they had a greater influence on the estimate.

The area-level coefficients were then multiplied by the relevant values for each MSOA, and added to the demographic random effects, as was the random effect for the MSOA in question. Then this value was added to the intercept and inverse logit-transformed to 
derive an estimate for the percentage of residents of each MSOA who felt they belonged or were trusting*.

Simple aggregation measures of belonging and trust were computed by computing the percentage of respondents in each MSOA who were coded as belonging or trusting.

\section{MRP results}

\section{Belonging}

Table 1 provides full information on the terms of the individual model for belonging, but the model is also described below.

\begin{tabular}{|c|c|c|c|}
\hline \multirow{15}{*}{ 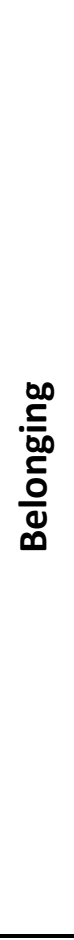 } & \multirow{2}{*}{$\begin{array}{l}\text { Fixed effects } \\
\text { Churn }\end{array}$} & \multicolumn{2}{|r|}{ SE } \\
\hline & & -3.351 & 1.364 \\
\hline & Unemployment & -0.058 & 0.008 \\
\hline & Random effects & SD & \\
\hline & Age & 0.312 & \\
\hline & Gender & 0.000 & \\
\hline & MSOA & 0.196 & \\
\hline & Local authority - Welsh-speakers & 0.091 & \\
\hline & Local authority - Non Welsh-speakers & 0.009 & \\
\hline & Local authority - Welsh only & 0.429 & \\
\hline & Local authority - Welsh and British only & 0.737 & \\
\hline & Local authority - English only & 0.443 & \\
\hline & Local authority - English and British & 0.634 & \\
\hline & Local authority - British only & 0.187 & \\
\hline & Local authority - All other identities & 0.190 & \\
\hline \multirow{5}{*}{$\stackrel{n}{\underline{n}}$} & Fixed effects & B & SE \\
\hline & No qualifications & -0.032 & 0.004 \\
\hline & Density & -0.006 & 0.002 \\
\hline & Random effects & SD & \\
\hline & Age & 0.403 & \\
\hline
\end{tabular}

\footnotetext{
* The primer by Kastellec, Lax, and Phillips [33] is an extremely useful resource for applying MRP: http://www.princeton.edu/ ikastell/MRP primer/mrp primer.pdf
} 


\begin{tabular}{ll} 
Gender & 0.075 \\
\hline MSOA & 0.124 \\
\hline Local authority - Welsh-speakers & 0.213 \\
\hline Local authority - Non Welsh-speakers & 0.010 \\
\hline Local authority - Welsh only & 0.116 \\
\hline Local authority - English only & 0.269 \\
\hline Local authority - English and British & 0.245 \\
\hline Local authority - British only & 0.179 \\
\hline Local authority - All other identities & 0.118 \\
\hline
\end{tabular}

Table 1. Summary of terms within the two MRP models.

Living in areas with higher levels of churn and unemployment were associated with decreased belonging. Increasing age was generally associated with greater belonging, and gender had no association. The terms for national identity and Welsh-speaking varied widely by local authority. Broadly, Welsh identities were protective, English and 'none of the above' identities showed decreased belonging, and British only was intermediate.

Trust

Table 1 provides full information on the terms of the individual model for trust, but the model is also described below.

Living in areas with higher proportions of people with no formal qualifications and higher population density were associated with lower trust. Age was broadly positively associated with trust and women had slightly greater trust than men. National identity's association with trust varied widely by local authority, but English-only identity was a 
consistent risk factor for low trust. Being a Welsh-speaker was protective in some local authorities and neutral elsewhere.
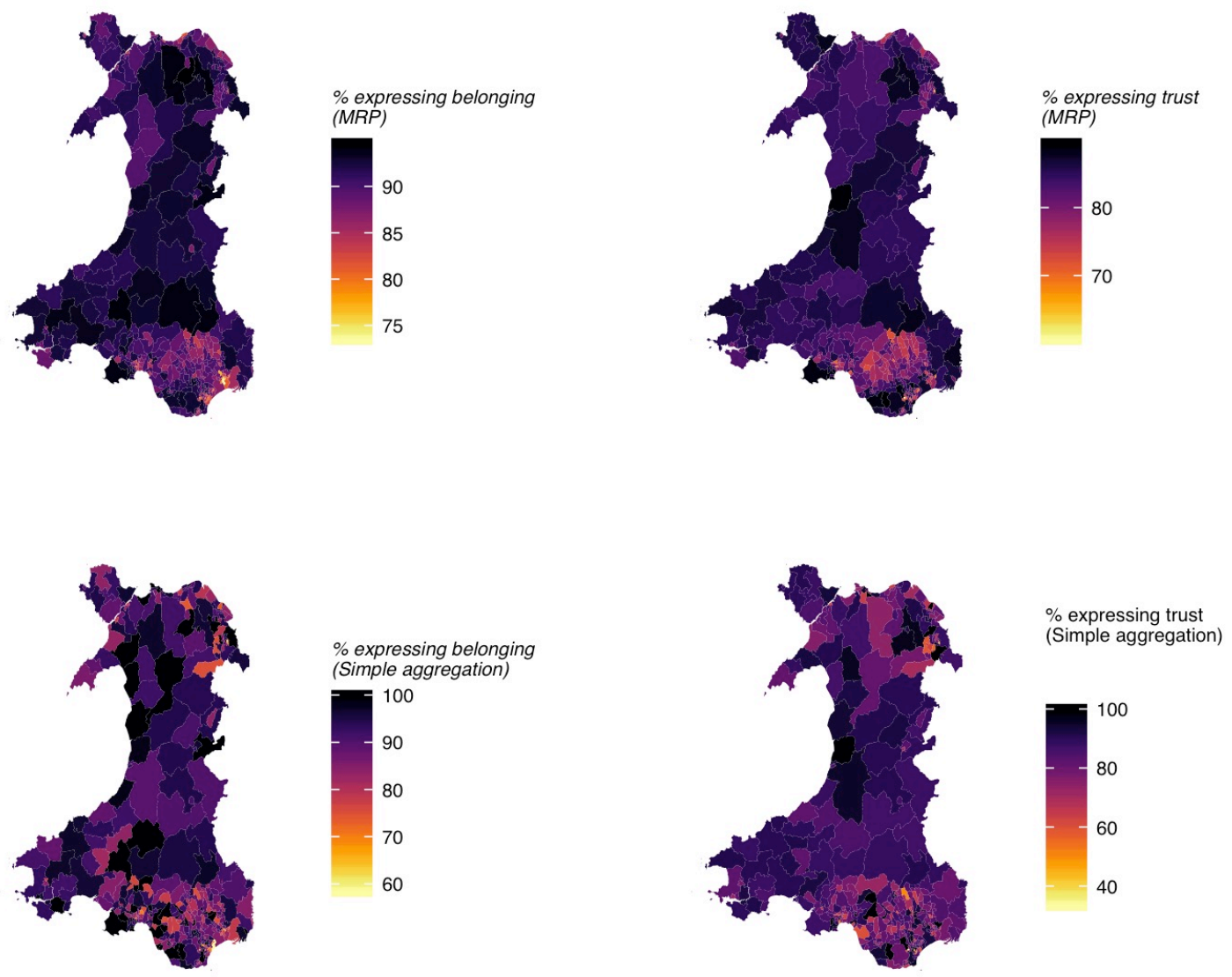

Figure 1. Maps of MRP-derived (top row) and simple aggregation-derived (bottom row) estimates of belonging (left-hand column) and trust (right-hand column) by MSOA.

Figure 1 shows maps of MRP and simple aggregation estimates of the prevalence of belonging and trust in each MSOA. Both are lower in the southern valleys and along the north coast.

MRP estimates range from 73-95\% for belonging and 61-89\% for trust, while simple aggregation estimates range from $58-100 \%$ for belonging and $33-100 \%$ for trust. 
Although it impossible to be sure that the greater range of simple aggregation estimates does not reflect important variance between MSOAs, it seems likely that this is a result of the huge margin of error associated with these estimates. Methodological work on MRP suggests that one reason MRP outperforms simple aggregation is by smoothing unreliable small samples towards a more reliable average[12]. More broadly, the geographical variability is promising as previous work has shown that this is an important precondition for successful application of MRP[11]. MRP estimates were correlated with simple aggregation measures for belonging $(\rho=.56)$, and trust $(\rho=.55)$. MRP estimates of belonging and trust were substantially correlated $(\rho=.75)$, but this correlation was lower for simple aggregation measures $(\rho=.28)$.

Finally, formal estimates of margin of error, including finite population correction, were computed for the simple aggregation approach for each MSOA. Margins of error for belonging had a mean of $12.6 \%$, ranging 5.7-23.8\%. Margins of error for trust averaged $15.7 \%$, ranging $7.1-29.7 \%$.

\section{Psychiatric data}

Data

Psychiatric admission data for 2017 from the Patient Episode Database for Wales were obtained from NHS Wales Informatics Service. A psychiatric admission was defined as an inpatient admission with a psychiatric treatment code under the Office of Population Censuses and Surveys Classification of Surgical Operations and Procedures system. Thus patients were defined by treatment, rather than by diagnosis or by bed type. Count of all unique individuals admitted in each MSOA, stratified by sex and three age bands $(18-34,35-64,65+)$, were computed. Where patients were admitted on multiple 
occasions, including in cases where they were admitted from multiple MSOAs, the first admission only was used. Office for National Statistics population estimates for 2017, stratified in the same way, were used to measure the at-risk population.

\section{Analyses}

Poisson generalised linear mixed effects models were fitted to the number of cases in each stratum of each MSOA with an offset of logged population at that stratum (to model cases as a rate), and random intercepts of MSOA, sex, age, and local authority. Simple models were fitted including a fixed effect of the social capital estimate (zscored) for each MSOA and a full model included fixed effects of social capital (zscored), sex, and age; and all of their interactions. Separate versions of the two models were fitted with the MRP estimates and simple aggregation estimates of belonging and trust, for a total of eight models.

The statistical significance of terms within each model were evaluated using $p$-values. The predictive validity of MRP and simple aggregation versions of each construct were compared across their respective simple models by assessing whether $95 \%$ confidence intervals of their rate ratios (RR) overlapped.

\section{Data Availability}

MRP estimates and the R script are provided in the supplementary materials. Raw data were obtained from third parties. The National Survey for Wales is available from the UK Data Service (https://www.ukdataservice.ac.uk/) but MSOA data must be requested from the Welsh Government directly. Psychiatric admission data are from NHS Wales Informatics Service's PEDW dataset, and can be requested from them, following 
necessary ethical permissions. Churn data are available from the Consumer Data Research Centre (https://www.cdrc.ac.uk/) following approval.

\section{RESULTS}

Figure 2 shows a map of psychiatric admissions rates by MSOA. Striking similarities with the maps of social capital are apparent, with high admission rates on the northern coast, patches of the southern coast, and in the southern valleys.

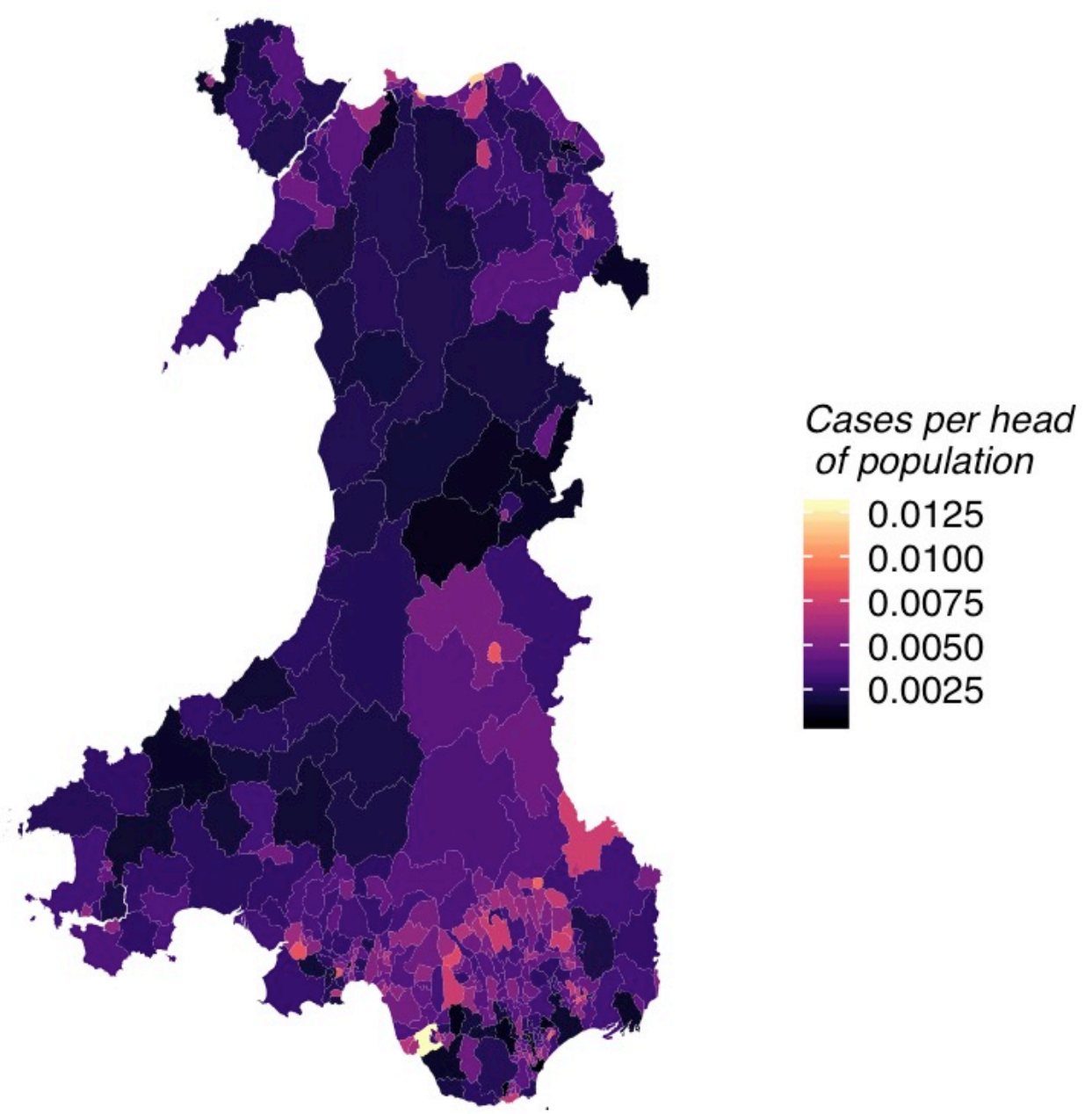


Figure 2. Map of psychiatric admission rate by MSOA. Light-coloured areas represent MSOAs with high admission rates and dark-coloured areas represent lower admission rates.

All model parameter are presented in Table 1 and scatterplots summarising the results are shown in Figure 3, but key results are described below.

\section{Belonging}

In the simple model, higher MRP estimates of belonging predicted lower psychiatric admission rates $\left(\mathrm{RR}=.77\left[\mathrm{RR}_{95 \% \mathrm{CI}}=.73-.81\right]\right)$. In the full model, belonging was protective in the 18-34 group $\left(\mathrm{RR}=.86\left[\mathrm{RR}_{95 \% \mathrm{CI}}=.79-.92\right]\right.$, reference group $)$ and more so in the 3564 group $(\mathrm{RR}=.71[\mathrm{RR} 95 \% \mathrm{CI}=.62-82])$. The slope for $65+$ year olds was equivalent to the 18-34 group.

High simple aggregation estimates were also significant predictor of lower admission rates in the simple model, but with much lower predictive validity $\left(\mathrm{RR}=.93\left[\mathrm{RR}_{95 \% \mathrm{CI}}=.89\right.\right.$ .97]). In the full model, simple aggregation estimates were not protective in the 18-34 group ( $R R=1.01\left[R_{95 \% \mathrm{CI}}=.94-1.08\right]$ ), but were modestly protective in the other two groups (35-64: RR=.89[RR $\left.\left.{ }_{95 \% C I}=.83-.95\right], 65+: R R=.90\left[\mathrm{RR}_{95 \% \mathrm{CI}}=.84-.97\right]\right)$.

Trust

In the simple model for trust, higher MRP estimates were also associated with lower admission rates $\left(\mathrm{RR}=.80\left[\mathrm{RR}_{95 \% \mathrm{CI}}=.77-.83\right]\right)$. In the full model, trust was protective in the 18-34 group (RR=.87 [RR95\%CI=.81-.92]) and was stronger in the 35-64 group $\left(\mathrm{RR}=.76\left[\mathrm{RR}_{95 \% \mathrm{Cl}}=.66-87\right]\right)$. 
Again, simple aggregation measures predicted admissions in the simple model, but less well than MRP measures (RR=.91[RR95\%CI=.87-.95]). In the full model, the simple aggregation measure did not predict admissions in the 18-34 group

$\left(\mathrm{RR}=.99\left[\mathrm{RR}_{95 \% \mathrm{Cl}}=.93-1.06\right]\right)$ but did in the 35-64 group $\left(\mathrm{RR}=.90\left[\mathrm{RR}_{95 \% \mathrm{Cl}}=.78-.1 .03\right]\right.$, note $p<.05$ but RR95\%CI crosses 0 ).
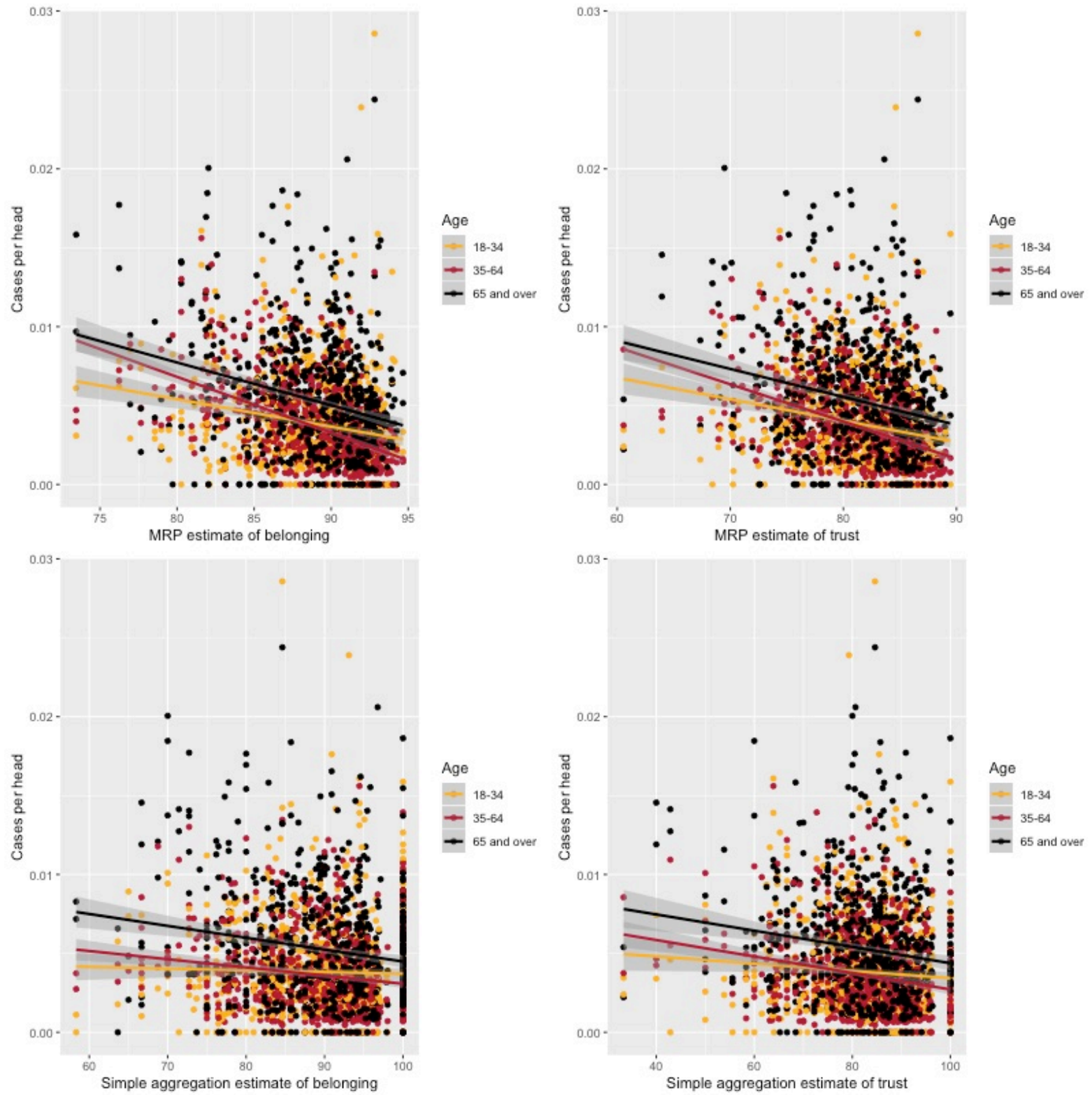

Figure 3. Scatterplots of social capital estimates against psychiatric admission rates for all stratified MSOAs 
**TABLE 2 HERE (currently at end of article)**

\section{Post-hoc control analyses}

As social capital and poverty are clearly intertwined[27,28], controlling for poverty in the main analysis of admission rates would produce results without a clear interpretation. That said, it seems worthwhile to assess whether the estimates have explanatory power beyond what measures of poverty provide.

The simple model was thus refitted including a term measuring the proportion of an MSOA's population receiving low income-related benefits (the income indicator from the Welsh Index of Multiple Deprivations). This reduced the slope of belonging, but it remained significant $\left(\mathrm{RR}=.91\left[\mathrm{RR}_{95 \% \mathrm{Cl}}=.85-.98\right]\right)$. The corresponding analysis with the simple aggregation measure, however, found no relationship with belonging $\left(\mathrm{RR}=1.02\left[\mathrm{RR}_{95 \% \mathrm{CI}}=.98-1.05\right]\right)$.

For the equivalent analyses for trust, neither the MRP $\left(R R=1.06\left[R_{95 \% \mathrm{CI}}=.98-1.14\right]\right)$ nor simple aggregation $\left(\mathrm{RR}=1.02\left[\mathrm{RR}_{95 \% \mathrm{Cl}}=.98-1.05\right)\right.$ terms were significant in their respective models, once accounting for income deprivation.

Belonging was not significant in the full model for belonging including income deprivation in the youngest age group ( $\left.R R=1.01\left[\mathrm{RR}_{95 \% \mathrm{CI}}=.93-1.09\right]\right)$, but its interaction with the age 35-64 group remained significant $\left(\mathrm{RR}=.84\left[\mathrm{RR}_{95 \% \mathrm{Cl}}=.72-.97\right]\right)$. Doing the same with the simple aggregation measures led to an apparent risk from belonging in the youngest group $\left(\mathrm{RR}=1.10\left[\mathrm{RR} \mathrm{R}_{9 \% \mathrm{Cl}}=.1 .04-1.17\right]\right)$, but significant interactions with the 
$35-64\left(\mathrm{RR}=.98\left[\mathrm{RR}_{95 \% \mathrm{Cl}}=.85-1.12\right]\right)$ and $65+$ age groups $\left(\mathrm{RR}=1.00\left[\mathrm{RR}{ }_{95 \% \mathrm{Cl}}=.86-1.14\right]\right)$ suggested that slopes for these groups were flat.

The equivalent full models for trust found that high MRP estimates were a risk factor in the 18-34 group after accounting for income deprivation $\left(\mathrm{RR}=1.15\left[\mathrm{RR}_{95 \% \mathrm{Cl}}=.1 .05\right.\right.$ 1.25]), but the significant interaction with the 35-64 group ( $\left.R R=1.01\left[\mathrm{RR}_{95 \% \mathrm{CI}}=.85-1.20\right]\right)$ meant that the slope was largely flat in this group. Equivalent results were found for the simple aggregation measures for trust: a risk factor for the 18-34 group $\left(\mathrm{RR}=1.10\left[\mathrm{RR}_{95 \% \mathrm{CI}}=.1 .04-1.17\right]\right)$ but a protective interaction with the 35-64 group $\left(\mathrm{RR}=1.01\left[\mathrm{RR}_{95 \% \mathrm{CI}}=.88-1.15\right]\right)$.

MRP belonging estimates were more correlated with low income rates $(\rho=-.76)$ than simple aggregation estimates ( $\rho=-.33)$. MRP trust estimates were extremely highly correlated with low income rates ( $\rho=-.89)$, with simple aggregation measures also correlated $(\rho=-.39)$.

\section{DISCUSSION}

MRP neighbourhood estimates of belonging and trust, facets of cognitive social capital, were computed using a large nationally representative survey. These estimates were predictive of geographic variability in psychiatric admission rates, particularly in 35-64 year olds. This technique represents a methodological advancement on existing approaches for estimating ecological cognitive social capital: MRP estimates outperformed simple aggregation measures in predictive validity, suggesting that the latter may underestimate low cognitive social capital as a risk factor. 
Simple aggregation measures were less correlated with each other than the corresponding MRP measures were, and were also less correlated with income deprivation. The simple aggregation estimates also had a wider range, including observations at $100 \%$. Part of this is due to the MRP estimates being modelled using some of the same data, but this may also speak to poorer reliability of the simple aggregation measures. Supporting this interpretation, margins of error were considerable for the simple aggregation approach - reaching almost 30 percentage points for the worst cases, but generally in the region of 15 points.

Clearly trust and belonging are distinct constructs and the decision to consider them both as facets of social capital is somewhat contentious. Trust is the subject of a great deal of research in its own right across the social sciences, while sense of belonging could be argued to be a consequence of social capital, rather than a facet of it. Both measures are presented separately so that readers who are sceptical about their appropriateness as measures of social capital can evaluate each alone. However, the results seem fairly qualitatively similar across the two measures, with the caveat that belonging appears less highly correlated with poverty than trust.

\section{Limitations}

The study had several limitations. Firstly, it is difficult to determine which variables should be part of an MRP model in a principled fashion. Here, variables were used that had face validity for being related to the strength and character of community - the turnover in residents, language, national identity - as well as demographic factors that are important in contemporary social science - socioeconomic deprivation, rurality, age. However, variable selection is a black box that may be vulnerable to $p$-hacking. 
Secondly, while MRP's application in political science has focused on predicting future voting behaviour using voting intention, here the outcome - psychiatric admission rates - is distinct from the construct being modelled - social capital. There is thus a question of construct validity that does not exist with voting intention. This, however is also an issue for the simple aggregation method.

Thirdly, this study did not measure individual-level social capital in the psychiatric data and thus it is unclear whether the protective factor is truly ecological, or whether it is an aggregated individual level protective factor. The area level measures may be predictive because they are indicative of the macro-level nature of a given community, or it may be because they are essentially a proxy for the likely individual-level social capital of any given resident. Other studies have controlled for individual cognitive social capital while testing for ecological effects[5], but this was not possible here. That said, the use of independent datasets for measuring exposure and ascertaining outcome has advantages.

Fourthly, it should be acknowledged that MRP estimates were highly correlated with income deprivation. While belonging remained protective for psychiatric admission after accounting for deprivation, trust did not. This was likely due to multicollinearity $(r \sim .9)$ between the two variables. Neither simple aggregation measures were protective after accounting for income deprivation, so this is not a limitation of MRP specifically, rather an issue with examining social capital without considering material deprivation, found elsewhere in the literature[29]. 
Fifthly, it was necessary to dichotomise trust and belonging in the individual level models because models predicting the raw Likert scale data had convergence issues and strikingly non-normal residuals. This is likely because Likert scale data do not meet the assumptions of interval data that a linear model makes. Dichotomising data is not ideal, potentially important information is discarded and small quantitative differences are reified into apparently qualitative differences, but major violations of model assumptions and potential simplifications of the model to support convergence seemed a worse option, so data were dichotomised. The cut-offs for dichotomisation were chosen to best reflect the distribution of the data rather than in order to maximise the significance of the modelling of psychiatric data. The cut-off for trust is also very similar to one used in a similar project in Japan[5].

Sixthly, although the use of routinely collected admissions data has advantages of being relatively uniformly and comprehensively collected across the whole of Wales, it has drawbacks. Only a tiny minority of people with mental health problems are admitted and these are based on clinical judgments. It is impossible to guarantee that the same criteria are being applied across Wales. Likewise, the individual-level social capital of patients themselves may affect their odds of being admitted - whether or not their problems can be managed in the community - after accounting for the severity of their problems, and this may be especially important in cases of involuntary admission. Geographical disparities may also exist in how likely patients are to come to the attention of services - urban-rural divides for example.

Finally, it is important to closely examine the question wording of the items used, rather than assuming they perfectly map onto the constructs of interest. The trust item is not 
the widely-used item from the United States General Social Survey ("Generally speaking, would you say that most people can be trusted or that you can't be too careful in dealing with people?"), which could limit the comparability of these analyses with other papers. However the latter item has been criticised for conflating trust and caution, and for having non-mutually exclusive response options[30]. The item featured in the National Survey for Wales was taken from the European Union Statistics on Income and Living Conditions - a major international survey series - so a great deal of potential comparative data exist. As for the item on belonging, the item is drawn from the Community Life Survey, a UK-wide government-commissioned survey on social action and community. It could be argued that it is ambiguous whether it measures a sense of belonging to the community or to the place itself, in contrast to measures used elsewhere[14], and thus whether it captures something straightforwardly social or a broader sense of identity.

\section{Strengths}

The major strength of the study is the innovative use of MRP to estimate ecological social capital. A key feature of MRP is that it 'borrows strength' from respondents with similar demographic features who live in different areas. This is particularly important where respondents are unevenly distributed, as was the case here. If using simple aggregation, researchers would have to choose between dropping areas with small sample sizes (e.g. [31]) and relying on extremely unstable and unrepresentative averages. Given that the reasons for low sample sizes - if driven by low response rates might well be correlated with health risk factors, this could be particularly problematic. Indeed, another similar study found that socially disorganised neighbourhoods had lower response rates to a questionnaire[32]. 
The use of separate datasets to measure exposure and outcome also avoids issues of contamination between exposure and outcome measures. Many studies into social capital and health use self-report measures to measure both exposure and outcome simultaneously, which could lead to correlated errors.

Finally, both datasets cover a whole country, with thousands of cases, and capture both rural and urban areas, supporting external validity.

\section{Potential criticisms of MRP}

One concern that could be raised about MRP is whether it privileges broader demographic and socioeconomic factors over specific local factors. This concern has some substance - MRP assumes that the relationship between demographic factors and the variable of interest is similar across different areas. That said, MRP has features that recognise the importance of local idiosyncrasies. Firstly, MRP includes random effects for each area to captures consistent commonalities across respondents from the area that are not captured by the demographic factors or area level predictors. Here, random effects for each MSOA as well as a higher level term for each local authority were included, in case there were factors that were detectable at a regional level but not at the MSOA level. Secondly, it is possible to allow demographic factors to vary in their weights across different areas. In this study, national identity and ability to speak Welsh were expected to vary in their value as cultural signifiers across different regions, and this was modelled using random slopes of these variables at the local authority level.

Needless to say, these strategies will not capture all local variations in social capital greater social capital in a particular subgroup of the population within a given area may 
not be captured because not enough members of that subgroup are captured, because the demographic feature that unites this group is not explicitly modelled (e.g. an active local church), or because high bonding capital in one group is mirrored by poor cognitive social capital in an outgroup for example. That said, in such instances it is not clear that simple aggregation would do a better job. Given simple aggregation's aforementioned high margin of error, where such estimates disagree with MRP estimates it would be dangerous to assume that MRP is failing to capture something important that simple aggregation is faithfully measuring.

Another issue is that MRP requires one to choose appropriate demographic and local factors used to model the variable of interest, whereas simple aggregation appears relatively assumption-free. This can lead to difficult conceptual questions, for example, here I took the decision to include area-level measures of socioeconomic deprivation in the model (unemployment and proportion of residents without formal qualifications) because they were powerful predictors of survey respondents' answers and because I am unconvinced that social capital levels can be meaningfully estimated while ignoring poverty, but this arguably leads to a conceptual blurring of different forms of capital. With simple aggregation, such issues do not arise, at least not explicitly.

A further issue of an explicitly model-based approach like MRP is epistemological. As stated above, the literature shows that one reason that MRP outperforms simple aggregation is by smoothing outliers back towards the average[12]. This, arguably, amounts to trusting the model more than one's data. MRP does of course outperform simple aggregation, possibly because simple aggregation also makes (and breaks) assumptions about survey data, that the point estimates it produces are reasonable 
values given the margin of error and potentially non-representative samples it uses. That said, this issue should not be dismissed - MRP's predictions could potentially be systematically wrong if the demographic structure assumed by the model glosses over meaningful sub-group variation, or if the predictive value of demographic markers is not constant across areas (and this is not modelled explicitly).

\section{Implications for policy}

Policymakers frequently make decisions about where to situate services to best meet need, and relying on administrative data to help make these decisions can lead to circular decision-making. MRP analyses of survey data represent a practical option to map variables which suggest need and disadvantage, which may help to place such decisions on a surer evidence base.

\section{Conclusions}

Effect sizes for MRP estimates were 2.5-3.6 times the size of those for simple aggregation (29\% and $25 \%$ vs $8 \%$ and $10 \%$ for belonging and trust respectively). This suggests that ecological social capital may have been substantially underestimated as a protective factor for mental health, due to unreliable estimates of exposure. Simple aggregation should not be used to measure ecological social capital, or indeed other similar ecological constructs, in the absence of explicit margin of error calculations. Where margins of error are unacceptable, MRP represents a practical alternative. Measurement of ecological social capital is an under-recognised issue in the field. MRP represents a novel potential solution. 
[1] Moore S, Kawachi I. Twenty years of social capital and health research: A glossary. J Epidemiol Community Health 2017;71:513-7. doi:10.1136/jech-2016-208313.

[2] Uphoff EP, Pickett KE, Cabieses B, Small N, Wright J. A systematic review of the relationships between social capital and socioeconomic inequalities in health: A contribution to understanding the psychosocial pathway of health inequalities. Int J Equity Health 2013;12:1-12. doi:10.1186/1475-9276-12-54.

[3] Ehsan AM, De Silva MJ. Social capital and common mental disorder: A systematic review. J Epidemiol Community Health 2015;69:1021-8. doi:10.1136/jech-2015205868.

[4] Giordano GN, Lindström M. Social capital and change in psychological health over time. Soc Sci Med 2011;72:1219-27. doi:10.1016/j.socscimed.2011.02.029.

[5] Hamano T, Fujisawa Y, Ishida Y, Subramanian S V., Kawachi I, Shiwaku K. Social Capital and Mental Health in Japan: A Multilevel Analysis. PLoS One 2010;5:e13214. doi:10.1371/journal.pone.0013214.

[6] Whitley R, Prince M. Is there a link between rates of common mental disorder and deficits in social capital in Gospel Oak, London? Results from a qualitative study. Heal Place 2005;11:237-48. doi:10.1016/j.healthplace.2004.05.002.

[7] Sariaslan A, Larsson H, D’Onofrio B, Långström N, Fazel S, Lichtenstein P. Does Population Density and Neighborhood Deprivation Predict Schizophrenia? A Nationwide Swedish Family-Based Study of 2.4 Million Individuals. Schizophr Bull 2015;41:494-502. doi:10.1093/schbul/sbu105.

[8] Kawachi I, Berkman LF. Social Ties and Mental Health. J Urban Heal Bull New York Acad Med 2001;78:458-67.

[9] Gelman A, Little TC. Poststratification Into Many Categories Using Hierarchical Logistic Regression. Surv Methodol 1997;23:127-135. 
[10] Park D, Gelman A, Balumi J. Bayesian Multilevel Estimation with Poststratification : State-Level Estimates from National Polls. Polit Anal 2004;12:375-85. doi:10.1093/pan/mph024.

[11] Buttice MK, Highton B, Highton B. Regression and Poststratification Perform with Conventional National Surveys ? Polit Anal 2019;21:449-67. doi:10.1093/pan/mpt017.

[12] Hanretty C, Lauderdale BE, Vivyan N. Comparing Strategies for Estimating Constituency Opinion from National Survey Samples*. Polit Sci Res Methods 2018;6:571-91. doi:10.1017/psrm.2015.79.

[13] Wang W, Rothschild D, Goel S, Gelman A. Forecasting elections with nonrepresentative polls. Int J Forecast 2015;31:980-991.

[14] Carpiano RM, Hystad PW. "Sense of community belonging" in health surveys : What social capital is it measuring ? Health Place 2011;17:606-17. doi:10.1016/j.healthplace.2010.12.018.

[15] Carpiano RM, Fitterer LM. Questions of trust in health research on social capital : What aspects of personal network social capital do they measure ? Soc Sci Med 2014;116:225-34. doi:10.1016/j.socscimed.2014.03.017.

[16] Putnam R. Making Democracy Work: Civic Traditions in Modern Italy. Princeton, NJ.: Princeton University Press,; 1993.

[17] Narayan D, Cassidy, Michael F. A dimensional approach to measuring social capital: Development and validation of a social capital inventory. Curr Sociol 2001;49:59-101.

[18] Carrasco MA, Bilal U. A sign of the times : To have or to be ? Social capital or social cohesion ? Soc Sci Med 2016;159:127-31. doi:10.1016/j.socscimed.2016.05.012.

[19] Office for National Statistics, Welsh Government. National Survey for Wales 2016- 
17 [Data Collection]. 2017. doi:http://doi.org/10.5255/UKDA-SN-8301-1.

[20] Lansley G, Li W, Longley P. Creating a Linked Consumer Register for Granular Demographic Analysis. J R Stat Soc Ser A 2019.

[21] Bates D, Maechler M, Bolker B. lme4: Mixed-effects modeling with R 2012.

[22] R Core Development Team. R: A language and environment for statistical computing. 2012;2.

[23] Balsom D. The Three-Wales Model. Natl. Quest. Again, Llandysul: Gomer Press; 1985.

[24] Evans DJ. Welshness in 'British Wales': negotiating national identity at the margins. Nations Natl 2019;25:167-90. doi:10.1111/nana.12390.

[25] Ghitza Y, Gelman A. Deep interactions with MRP: Election turnout and voting patterns among small electoral subgroups. Am J Pol Sci 2013;57:762-76. doi:10.1111/ajps.12004.

[26] Odell E. nomisr: Access Nomis UK Labour Market Data With R. R Package 2018. doi:10.5281/zenodo.1157908.

[27] Bourdieu P. The forms of capital. Richardson, J., Handb. Theory Res. Sociol. Educ. Westport, CT Greenwood, 1986, p. 241-58.

[28] Stafford M, Bartley M, Sacker A, Marmot M, Wilkinson R, Boreham R, et al. Measuring the social environment: Social cohesion and material deprivation in English and Scottish neighbourhoods. Environ Plan A 2003;35:1459-75. doi:10.1068/a35257.

[29] Harpham T, Grant E, Rodriguez C. Mental health and social capital in Cali , Colombia 2004;58:2267-77. doi:10.1016/j.socscimed.2003.08.013.

[30] Naef M, Schupp J. Measuring Trust : Experiments and Surveys in Contrast and Combination. Inst Study Labor Discuss Pap No 40872009. 
[31] Aminzadeh K, Denny S, Utter J, Milfont TL, Ameratunga S, Teevale T, et al. Neighbourhood social capital and adolescent self-reported wellbeing in New Zealand: A multilevel analysis. Soc Sci Med 2013;84:13-21. doi:10.1016/j.socscimed.2013.02.012.

[32] Kirkbride JB, Boydell J, Ploubidis GB, Morgan C, Dazzan P, McKenzie K, et al. Testing the association between the incidence of schizophrenia and social capital in an urban area. Psychol Med 2008;38:1083-94. doi:10.1017/S0033291707002085.

[33] Kastellec JP, Lax JR, Phillips J. Estimating State Public Opinion With Multi-Level Regression and Poststratification using R. Unpubl Manuscr 2016:13. doi:10.1201/b13872-5. 


\begin{tabular}{|c|c|c|c|c|c|c|c|c|c|c|c|c|c|c|c|c|}
\hline & \multicolumn{16}{|c|}{ Belonging } \\
\hline & \multicolumn{8}{|c|}{ MRP } & \multicolumn{8}{|c|}{ Simple Aggregation } \\
\hline & \multicolumn{4}{|c|}{ Simple model } & \multicolumn{4}{|c|}{ Full model } & \multicolumn{4}{|c|}{ Simple model } & \multicolumn{4}{|c|}{ Full model } \\
\hline & $\mathrm{RR}$ & $95 \% \mathrm{Cl}$ & z & $\mathrm{p}$ & $\mathrm{RR}$ & $95 \% \mathrm{Cl}$ & z & $\mathrm{p}$ & $\mathrm{RR}$ & $95 \% \mathrm{Cl}$ & Z & $\mathrm{p}$ & $\mathrm{RR}$ & $95 \% \mathrm{Cl}$ & Z & $p$ \\
\hline Intercept & & & -38.82 & $>.0001$ & & & -119.38 & $>.0001$ & & & -39.56 & $>.0001$ & & & -121.49 & $>.0001$ \\
\hline Belonging & .77 & $.74-.80$ & -12.85 & $>.0001$ & .86 & $.81-.92$ & -4.62 & $>.0001$ & .93 & $.89-.97$ & -3.54 & .0004 & 1.01 & $.94-1.08$ & .19 & .8480 \\
\hline $35-64$ group & & & & & .84 & $.77-.91$ & -4.44 & $>.0001$ & & & & & .86 & $.80-0.93$ & -3.82 & .0001 \\
\hline $65+$ group & & & & & 1.59 & $1.47-1.71$ & 11.72 & $>.0001$ & & & & & 1.60 & $1.48-1.72$ & 12.16 & $>.0001$ \\
\hline Male & & & & & 1.16 & $1.07-1.26$ & 3.48 & .0005 & & & & & 1.17 & $1.08-1.27$ & 3.83 & .0001 \\
\hline Belonging * 35-64 group & & & & & .83 & $.77-.89$ & -5.27 & $>.0001$ & & & & & .89 & $.83-.95$ & -3.22 & .0013 \\
\hline Belonging $* 65+$ group & & & & & .97 & $.91-1.05$ & -.70 & .4857 & & & & & .90 & $.84-.97$ & -2.64 & .0082 \\
\hline Belonging * Male & & & & & .96 & $.90-1.04$ & -.98 & .3267 & & & & & .97 & $.9-1.05$ & -.66 & .5116 \\
\hline $35-64$ group * Male & & & & & 1.22 & $1.1-1.36$ & 3.73 & .0002 & & & & & 1.22 & $1.1-1.35$ & 3.89 & .0001 \\
\hline $65+$ group * Male & & & & & .82 & $.73-.91$ & -3.68 & .0002 & & & & & .81 & $.73-.90$ & -3.91 & .0001 \\
\hline $\begin{array}{c}\text { Belonging * } 35-64 \text { group* } \\
\text { Male }\end{array}$ & & & & & 1.03 & $.94-1.12$ & .56 & .5781 & & & & & 1.05 & $.95-1.16$ & .99 & .3214 \\
\hline \multirow[t]{5}{*}{ Belonging $* 65+$ group $*$ Male } & & & & & .99 & $.89-1.10$ & -.19 & .8485 & & & & & 1.02 & $.92-1.14$ & .45 & .6520 \\
\hline & \multicolumn{16}{|c|}{ Trust } \\
\hline & \multicolumn{8}{|c|}{ MRP } & \multicolumn{8}{|c|}{ Simple Aggregation } \\
\hline & \multicolumn{4}{|c|}{ Simple model } & \multicolumn{4}{|c|}{ Full model } & \multicolumn{4}{|c|}{ Simple model } & \multicolumn{4}{|c|}{ Full model } \\
\hline & $\mathrm{RR}$ & $95 \% \mathrm{Cl}$ & Z & $\mathrm{p}$ & $\mathrm{RR}$ & $95 \% \mathrm{Cl}$ & Z & $\mathrm{p}$ & $\mathrm{RR}$ & $95 \% \mathrm{Cl}$ & Z & $\mathrm{p}$ & $\mathrm{RR}$ & $95 \% \mathrm{Cl}$ & Z & $\mathrm{p}$ \\
\hline Intercept & & & -40.05 & $>.0001$ & & & -143.75 & $>.0001$ & & & -39.71 & $>.0001$ & & & -124.46 & $>.0001$ \\
\hline Trust & .80 & $.77-.83$ & -11.86 & $>.0001$ & .87 & $.81-.92$ & -4.34 & $>.0001$ & .91 & $.87-.95$ & -4.59 & .7700 & .99 & $.93-1.06$ & -.29 & .7700 \\
\hline $35-64$ group & & & & & .85 & $.79-.92$ & -4.09 & $>.0001$ & & & & & .86 & $.80-.93$ & -3.78 & .0002 \\
\hline $65+$ group & & & & & 1.60 & $1.48-1.72$ & 11.93 & $>.0001$ & & & & & 1.59 & $1.48-1.72$ & 12.12 & $>.0001$ \\
\hline Male & & & & & 1.16 & $1.06-1.25$ & 3.43 & .0006 & & & & & 1.16 & $1.07-1.26$ & 3.66 & .0003 \\
\hline Trust * $35-64$ group & & & & & .88 & $.82-.94$ & -3.50 & .0005 & & & & & .91 & $.85-.98$ & -2.59 & .0095 \\
\hline
\end{tabular}




\begin{tabular}{|c|c|c|c|c|c|c|c|c|}
\hline Trust $* 65+$ group & 1.01 & $.94-1.09$ & .27 & .7882 & .94 & $.88-1.02$ & -1.51 & .1323 \\
\hline Trust * Male & .94 & $.87-1.02$ & -1.47 & .1408 & .94 & $.87-1.01$ & -1.79 & .0732 \\
\hline $35-64$ group * Male & 1.22 & $1.10-1.35$ & 3.69 & .0002 & 1.22 & 1.1-1.35 & 3.82 & .0001 \\
\hline $65+$ group $*$ Male & .82 & $.74-.91$ & -3.64 & .0003 & .82 & $.73-.91$ & -3.79 & .0002 \\
\hline Trust * 35-64 group* Male & 1.01 & $.92-1.11$ & .19 & .8492 & 1.02 & $.93-1.12$ & .39 & .6952 \\
\hline Trust $* 65+$ group $*$ Male & 1.03 & $.93-1.14$ & .52 & .6055 & 1.04 & $.94-1.16$ & .83 & .4080 \\
\hline
\end{tabular}

